\title{
Meso-Alpha Scale Tropospheric Interactions within the Western Mediterranean Basin: Statistical Results Using 15-Year NCEP/NCAR Reanalysis Dataset
}

\author{
J. L. Palau and F. Rovira \\ Fundación Centro de Estudios Ambientales del Mediterráneo (CEAM), Parque Tecnológico, C/ Charles R. Darwin 14, València, \\ 46980 Paterna, Spain
}

Correspondence should be addressed to J. L. Palau; joseluis@ceam.es

Received 3 July 2014; Revised 14 October 2014; Accepted 15 October 2014

Academic Editor: Ismail Gultepe

Copyright (C) 2015 J. L. Palau and F. Rovira. This is an open access article distributed under the Creative Commons Attribution License, which permits unrestricted use, distribution, and reproduction in any medium, provided the original work is properly cited.

\begin{abstract}
After a 15-year average of the reanalyses meteorological data provided by NCEP/NCAR, this paper shows the mean seasonal evolution, between April and October, of the tropospheric dynamics in the Western Mediterranean Basin (WMB). As shown in this paper, it is the result of the meso-alpha interaction between the daily oscillation of coastal thermally driven circulations around the basin and the daily pulsation of sinking speeds over areas of the Western Mediterranean Sea. Furthermore, from the 15-year average, a statistically significant correlation has been found between these processes (the daily oscillation of sea breezes and the daily pulsation of subsidence/convergence on the WMB). The quantification of this persistent link between these tropospheric processes elucidates their teleconnection at the meso-alpha scale and the seasonal evolution of the strength of this linkage. Test statistics are greater than critical values for the $5 \%$ significance level of the F-distribution. Besides, we have estimated a generalised diurnal compensatory subsidence over the Western Mediterranean Sea with a maximum mean sinking (subsidence) motion of up to $-0.2 \mathrm{~cm} / \mathrm{s}$ at $18: 00 \mathrm{~h} \mathrm{UTC}$ and $1000 \mathrm{hPa}$ and a nocturnal generalised mean upward (convergence) motion of up to $0.05 \mathrm{~cm} / \mathrm{s}$ at 00:00 h UTC and $1000 \mathrm{hPa}$.
\end{abstract}

\section{Introduction to Meso-Alpha Scale Meteorological Persistence on the Western Mediterranean Basin}

The determination of the main circulation modes of the atmospheric pathways, and its seasonal variability in the Western Mediterranean basin (WMB), is a relevant issue to integrate feedbacks driving climate change in terms of precipitation regimes, secondary pollutants production, ventilation conditions, and so forth.

The characterisation of atmospheric flow regimes, its seasonality and statistical significance, allows the assessment of the representativeness of selected case studies to evaluate the impact of air quality on climate and, besides, feedbacks between the different components involved in the climate change within the Mediterranean environment (water vapour budget, import-export pollutant pathways in the Mediterranean, land-use change, etc).
Typical daily cycles of wind direction at coastal sites around the Western Mediterranean Sea are characterized by the alternation of diurnal inland sea breezes and nocturnal drainage winds (Figure 1). Shape and width of these cycles depend strongly on the season of the year since they are thermally driven atmospheric circulations. Figure 1 shows examples of different daily average cycles of wind directions at four coastal sites around the WMB. Same features are easily recognizable: seasonality of wind direction (autumn versus summer), duration of diurnal sea breeze (longer in summer than in autumn), land drainage wind directions (almost the same regardless of the season), and diurnal sea breeze directions (changing during the day, especially in summer).

Despite the fact that NCEP/NCAR reanalysis resolution [1] does not fit the requirements to give a reliable view of the strength of meso-beta (or gamma) scale processes in the Western Mediterranean basin [2], it is possible to use it to 

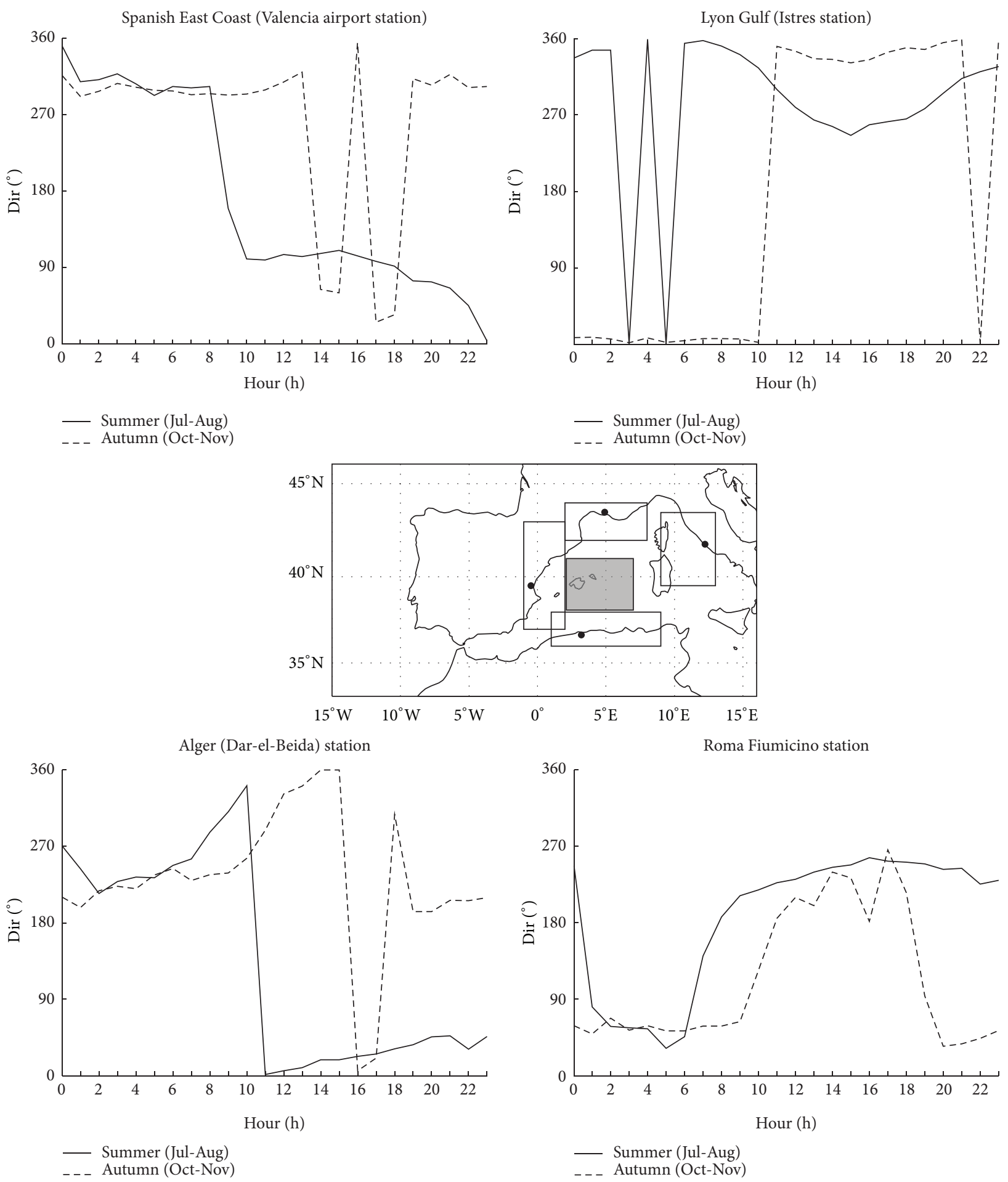

FIGURE 1: Daily average of wind directions measured simultaneously at four sites around the Western Mediterranean basin. Continuous line corresponds with summer daily average and dotted line with autumn daily average. Central figure shows the geographical position of the four selected meteorological stations; shaded rectangle represents the area where divergence values were calculated.

obtain a picture showing the general and prevailing mesoalpha scale features where mesoscale tropospheric circulations are embedded [3-6].

In the study presented in this paper, we have used a 6hourly reanalysis dataset, over the range of dates between
April and October, of mean daily data from 1991 to 2005 (15 years). This database is freely provided by NOAA/OAR/ESRL PSD (Boulder, Colorado, USA) on Internet (web site http://www.esrl.noaa.gov/psd/). These reanalysis composite weather maps are constructed by NCEP/NCAR following 

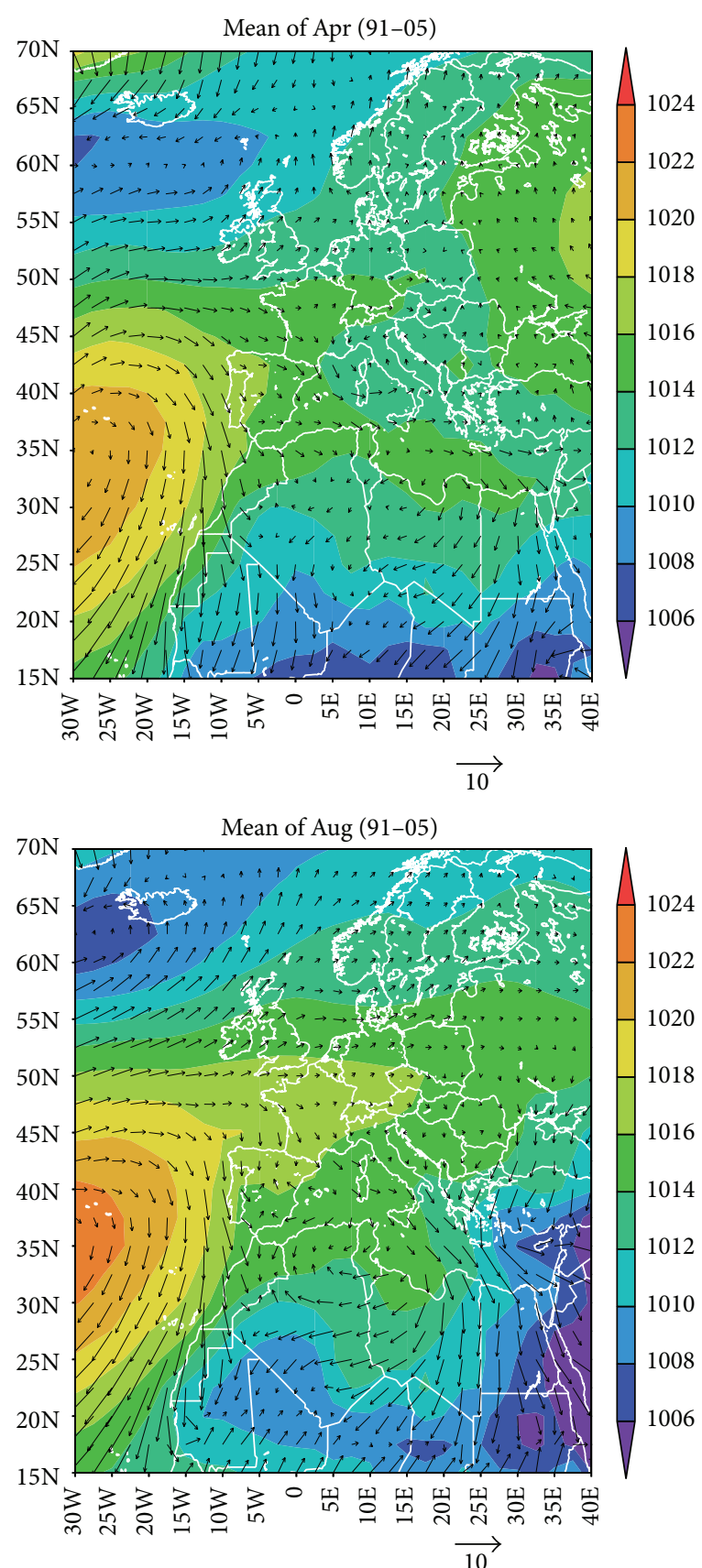

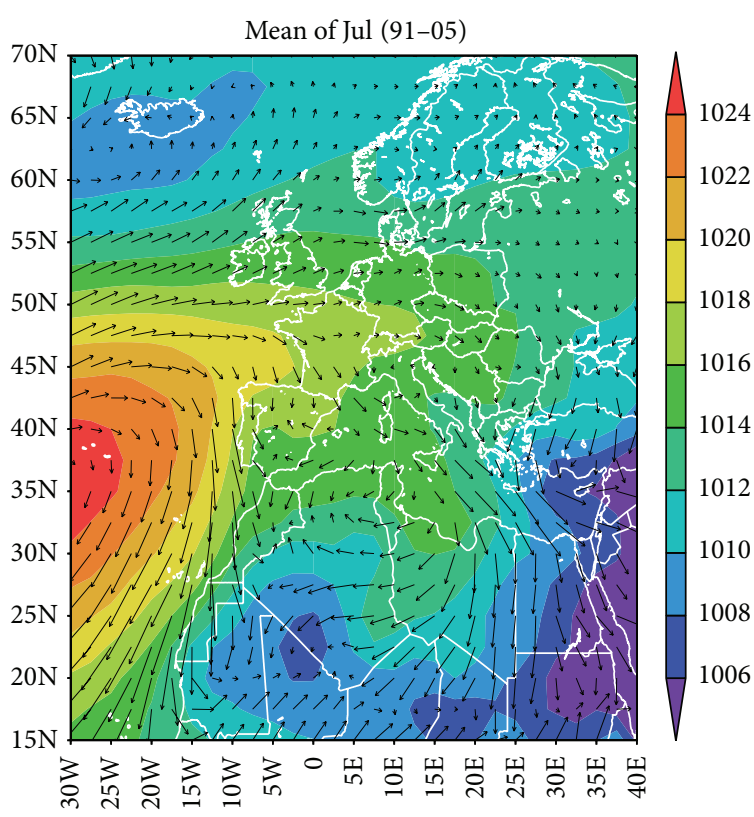

$\overrightarrow{10}$

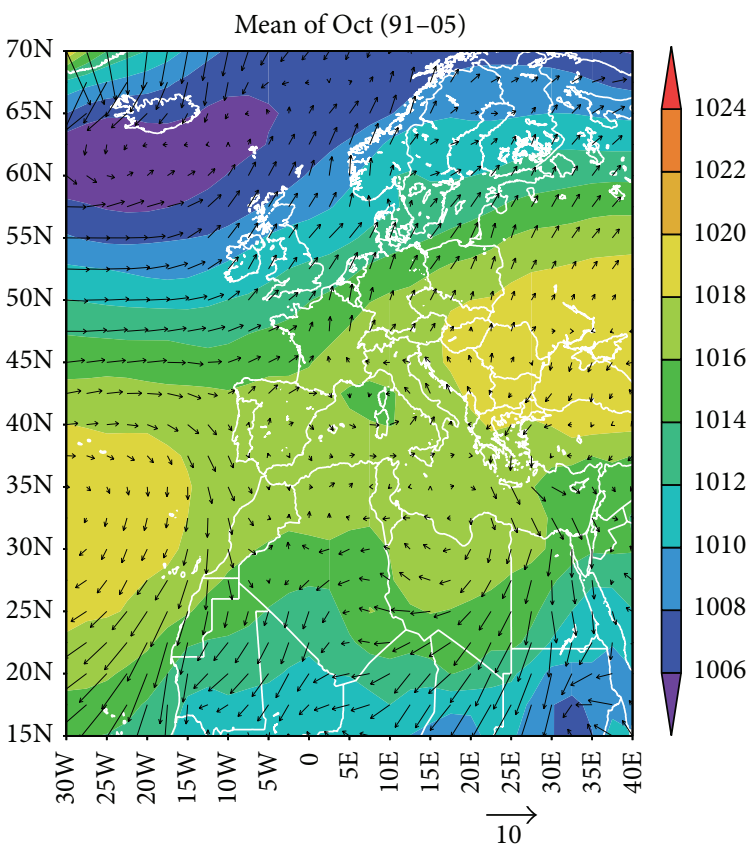

Figure 2: Monthly mean composite maps of Wind and Surface Pressure for the 15-year period (1991-2005).

the procedure of Kalnay et al. [7] and have a spatial resolution of $2.5 \times 2.5$ degrees with 17 pressure levels.

We have calculated both the hourly and monthly means, for the 15-year period, of sea level pressure and horizontal wind field to identify the persistence and the seasonal-todaily variability of these meteorological fields (Figures 2 and 3) since the WMB coastal sea breezes, their return flows aloft and their compensatory subsidence over the sea, become the most characteristic wind circulation in the troposphere from approximately late April to early October $[8,9]$.
At first sight, persistence of Azores Anticyclone through the selected seven months stands out clearly (monthly mean sea level pressure indicated as shaded colours in Figure 2), with the greatest strength in July and the weakest mean sea-level pressure values in October. The reanalysis means also show the persistence in the extension of the Saharan Low over the Iberian Peninsula during the summer season. This extension appears in the mean weather maps as a consequence of the formation of the Iberian Thermal Low that, according to previous results studying mesoscale processes in the region, acquires a quasi-permanent character in 

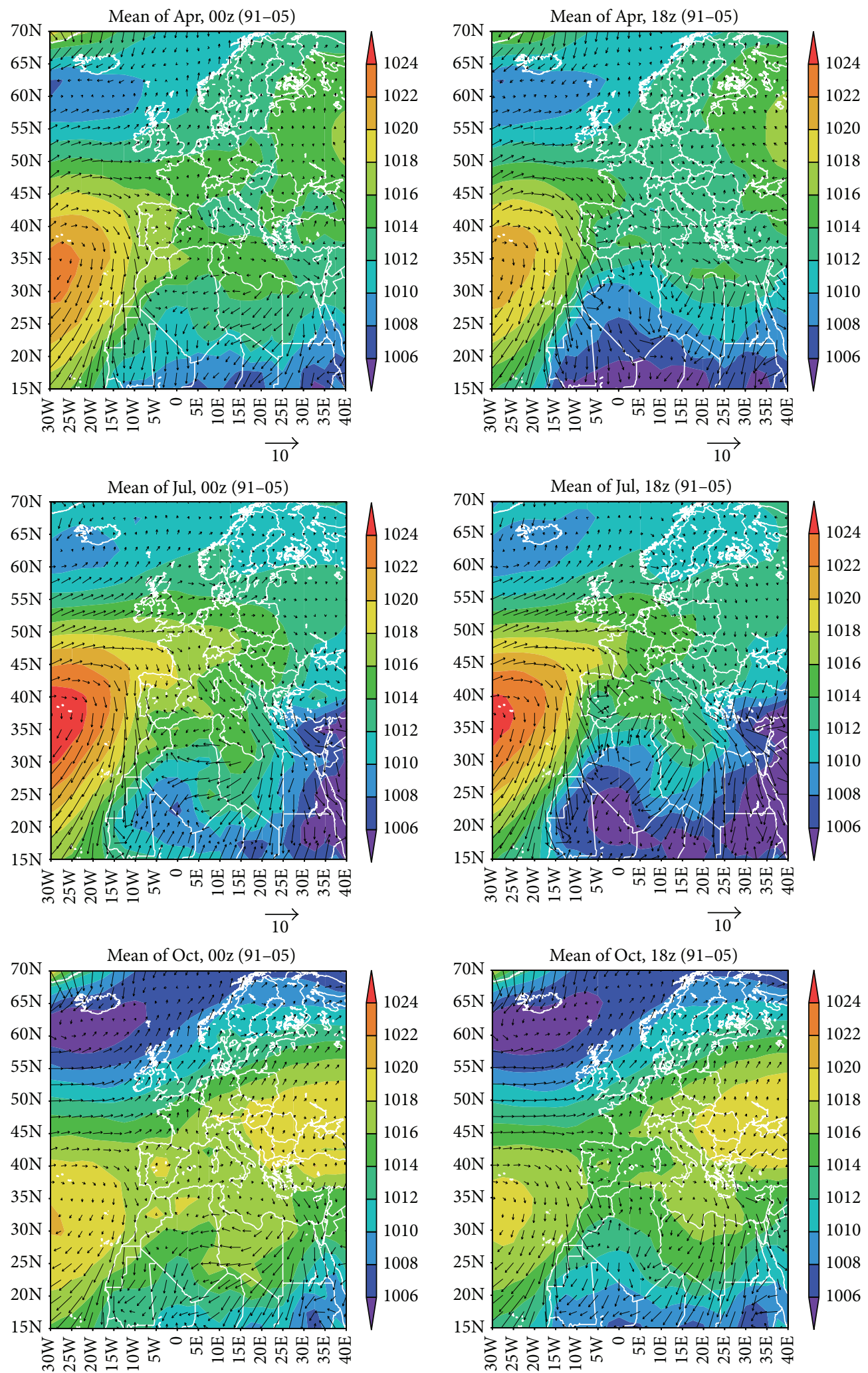

$\overrightarrow{10}$

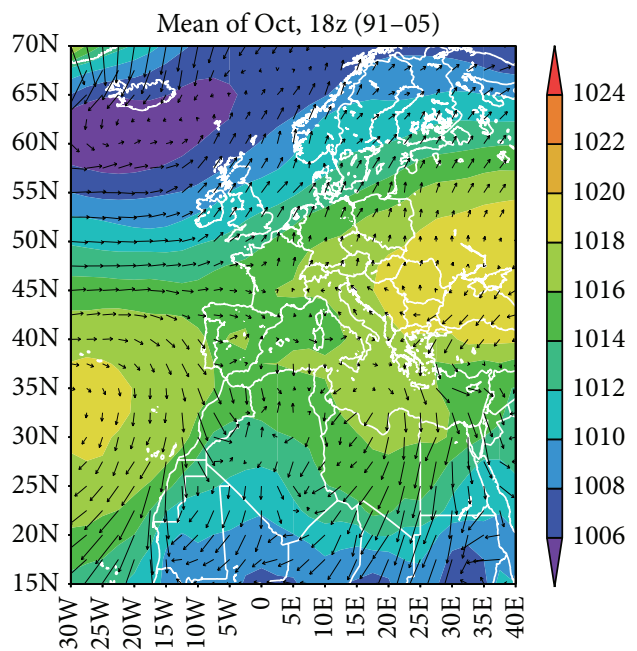

$\overrightarrow{10}$

FIGURE 3: Monthly mean composite maps of Wind and Surface Pressure, at 00:00 h and 12:00 h UTC, for the 15-year period (1991-2005). 
summer and constitutes the most frequent and outstanding meteorological scenario in the region $[8,10,11]$.

As wind vectors in composite maps are the result of a 15year average, persistence in wind direction will result in a well-defined vector whilst vectors with a near-zero module represent a high variability in wind direction on that area during the averaging period [12]. During the late-spring and summer months, variability is higher because wind fields in the Mediterranean basin are dominated by thermally driven processes (mesoscale circulations) whilst, during the rest of the year, general circulation (synoptic flows) prevails with a more persistent west-component flow direction [13].

At this temporal and spatial resolution the structure of mean wind fields for the different months is quite smooth, although some topographically linked features can be glimpsed during the late-spring and summer months (Figure 2) and driven by solar heating (i.e., during the diurnal hours, Figure 3). Thus, some of the convergence areas identified in the Mediterranean basin by Millán et al. $[4,10]$ appear on the main mountain barriers surrounding the Mediterranean Sea as vector convergence of the mean horizontal wind vectors.

Compensatory subsidence areas over the sea [4] are the consequence of the formation of deep convergence areas on high mountain barriers (as it is the case for the Alps and the Atlas) and on big Peninsulas (as those link to the Thermal Lows on Iberia and Anatolia). These sinking areas appear as divergences of the wind vectors in the mean composite maps (Figures 2 and 3).

Convergence and compensatory subsidence are mesoscale processes link to solar heating of mountains slopes and therefore have a daily cycle with maximum values on the afternoon. During nighttime, thermal circulations relax and divergence of wind fields over the sea disappear (Figure 3) and general (synoptic) flows prevail.

Comparing the daytime with nighttime directions of horizontal wind vectors along the coastline of the Mediterranean a pulsating behaviour is evident. This pulsation is more evident on the Western side of the basin, with vectors oriented towards the sea during nighttime indicating a generalised convergence on the sea and during daytime vectors oriented inland (Iberian Peninsula) or parallel to the coast (as on the Golf of Lyon and on the Liguria Sea). This behaviour is seasonally dependent as it depends on the intensity and duration of the solar heating.

Comparing summer months with autumn and spring months (Figure 2), the reinforcement of the Atlantic Anticyclone and, consequently, an increase in wind speed are evident (Figure 2). In summer time, daytime is longer than the rest of the year; thus, when calculating statistics, diurnal processes have a bigger weight on a daily basis than nocturnal circulations. This results in an increase of the module of wind vectors in composite maps in areas where daytime wind speed is much higher than nighttime winds (as, for example, is the case for sea breeze winds versus drainage winds in coastal areas).

Summarizing, the following persistence has been observed during the summer months when comparing the mean composite maps with the rest of the months (April, May, and October):

(i) there is diurnal divergence of horizontal wind field on the Western Mediterranean and the Black Sea;

(ii) on the Eastern coasts of the Iberian Peninsula, Eastern winds are increased in mean composite maps of June, July, and August because of the increase of the number of hours with sea breeze flows;

(iii) mean composite maps show an increase of the convergence along the Atlas and Alps barriers during diurnal hours;

(iv) north-western winds are reinforced on Golf of Lyon, Liguria Sea, and North Italy coasts during the daytime;

(v) on coastal areas of Libya and Egypt mean composite maps show a notable increase of wind speeds flowing towards South;

(vi) there is a subsidence area on the Libya coasts (SidraTripoli Gulf) that intensifies during the daytime and gives rise to an intense cyclonic movement of surface winds constituting an outflow region of air masses over the Mediterranean towards the Atlantic (running parallel to the southern faces of Atlas ridge) and towards the Earth equator. This circulation is not so evident in autumn.

Now, the question arising is whether all these processes, seasonally dependent and following a daily cycle, are all linked together leading a generalized divergence (day) and convergence (night) on the whole WMB.

Thus, the objectives of this work are, first, to quantify the seasonality and the mean daily cycle of the prevailing compensatory subsidence over the Western Mediterranean Sea and, second, to analyse the relationship between the seasonality and the diurnal oscillation of the strength of compensatory motions (subsidence and convergence) over the Sea and the daily cycles of mesoscale flows (diurnal sea breezes and nocturnal land drainages) around the coasts of the WMB. Our results, obtained from the 6-hourly reanalysis dataset provided by NCEP/NCAR over the range of dates between April and October, point out the relationship between the seasonality and the diurnal oscillation of the strength of compensatory motions (subsidence and convergence) over the Western Mediterranean Sea and the daily cycles of mesoscale flows (diurnal sea breezes and nocturnal land drainages) around the coasts of the basin; that is, how tropospheric dynamics in the Western Mediterranean is the result of the interaction between the daily strengthening (day) and weakening (night) thermally driven circulations and their compensatory motions over the Sea.

\section{Subsidence on the Western Mediterranean Basin from NCEP/NCAR Reanalysis Dataset}

2.1. Estimates of Mean Vertical Velocity from Mean Horizontal Divergence. NCEP/NCAR reanalysis dataset provides, 


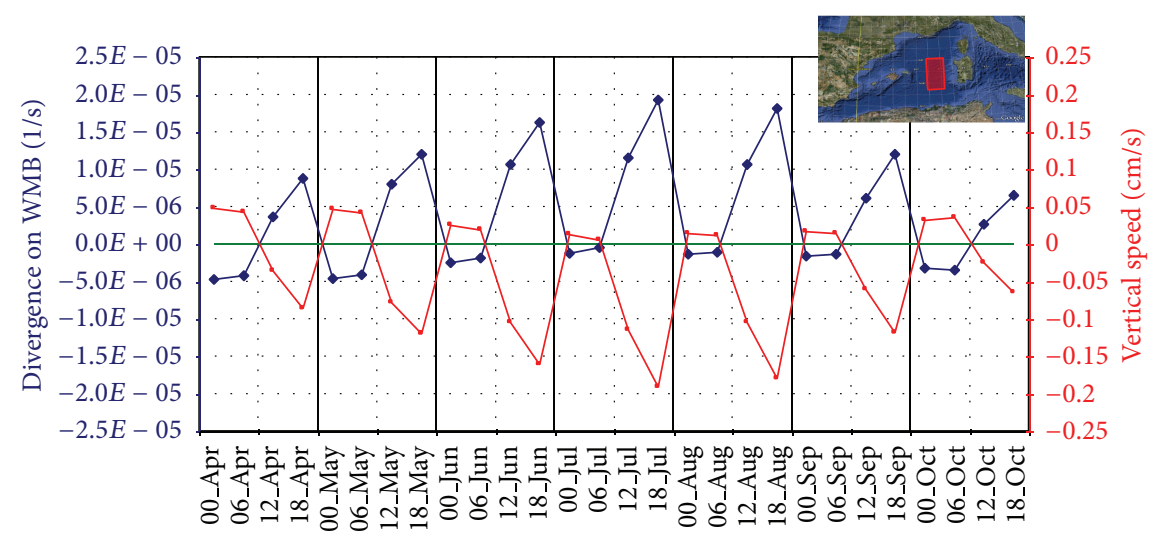

FIGURE 4: Monthly evolution of the hourly variation of the mean divergence (blue) and mean sinking speed (red) of lower atmospheric layers over the WMB. On the top-right corner, representation of the area where averages were calculated (between Balearic archipelago and Sardinia).

among others, horizontal wind speed components $(u, v)$, geopotential height, and temperature values for the different pressure levels. It also provides omega $(\omega)$, defined as $\omega \equiv$ $\mathrm{d} p / \mathrm{d} t$, usually called the "omega vertical motion," that is, the pressure change following the motion, which plays the same role in the isobaric coordinate system that $w \equiv \mathrm{d} z / \mathrm{d} t$ (vertical velocity) plays in height coordinates [14].

It is possible to calculate the divergence fields and the vertical velocity, $w \equiv \mathrm{d} z / \mathrm{d} t$, for a given pressure level, from the continuity equation (in height coordinates) and the vertical density distribution of the air in the lower troposphere because when there is vertical motion the compressibility associated with the height dependence of density must be taken into account.

In the continuity equation, the first term is the local density change (or rate of mass increase per unit volume) and the second term is the mass flux:

$$
\begin{aligned}
& \frac{\partial \rho}{\partial t}+\vec{\nabla} \cdot(\rho \vec{V})=0, \\
& \rho=\rho_{0} e^{-\left(z-z_{0}\right) M g / R T},
\end{aligned}
$$

where $\rho$ is the air density at a given height $(z), \rho_{0}$ is the air density at a reference height $\left(z_{0}\right), t$ is time, $\vec{V}$ is the vector wind speed, $g$ is the acceleration due to gravity, $R$ is the Ideal Gas Constant, $T$ is the air absolute temperature, and $M$ is the air molecular mass.

For a given time, as, for example, $00 \mathrm{~h}$ or $12 \mathrm{~h}$ in the reanalysis fields, it is assumable that air density remains virtually constant over time at one pressure level in the reanalysis fields; then the mass flux using the basic state density is not divergent (1). Then, from (1), it is direct to obtain the following relationship:

$$
w=-\frac{R T}{M g}\left(\frac{\partial u}{\partial x}+\frac{\partial v}{\partial y}+\frac{\partial w}{\partial z}\right)
$$

Considering horizontal divergence as known data calculated from the reanalysis fields and reordering (2) as a differential equation for the vertical velocity,

$$
\frac{\partial w}{\partial z}+\frac{w}{R T / M g}=-\left(\frac{\partial u}{\partial x}+\frac{\partial v}{\partial y}\right)_{z}
$$

Then, solving this first order differential equation for the vertical velocity, it is direct to obtain the vertical wind speed (in height coordinates) as a function of the horizontal divergence at a given height $(z)$ :

$$
w=\frac{R T}{M g}\left(\frac{\partial u}{\partial x}+\frac{\partial v}{\partial y}\right)_{z}\left[\exp \left(\frac{-z+z_{0}}{R T / M g}\right)-1\right]
$$

2.2. Daily Evolution and Seasonality of Subsidence on the Western Mediterranean. From the NCEP/NCAR 6-hourly reanalysis database, we have also obtained the "mean day" for each month, averaging hourly all the days of each month through the 15 years considered (1991-2005). Thus, we have obtained the 6-hourly mean-month evolution of the horizontal wind divergence at the first pressure level and, from (3), the corresponding vertical wind speed at that level.

To quantify the seasonality and the daily evolution of subsidence of air masses on the Western Mediterranean that are identified in NCEP/NCAR composite maps (Figures 2 and 3), we have averaged both the horizontal divergence wind field and the vertical wind speed on an area within the Western Mediterranean, between the Balearic archipelago and Sardinia, where reanalysis horizontal wind field indicates stronger mean subsidence (Figure 4). Vertical wind speed and horizontal divergence, as expected, are anticorrelated and, therefore, positive values of divergence indicate downward motion of air masses, generating relative high pressure values at the surface level. During summer months, when coastal convergences are strongly developed all along the coasts around the whole Western Mediterranean, maximum mean values of vertical wind speed, at $1000 \mathrm{hPa}$, range between 
TABLE 1: Statistics for linear regressions (coastal wind direction as a function of the divergence over the Mediterranean) over the four selected areas in the WBM.

\begin{tabular}{lcccccc}
\hline \multicolumn{7}{c}{ Statistics between coastal wind direction and divergence over the sea } \\
& Night & & & Day & \\
& Linear correlation & $R^{2}$ & Significance level & Linear correlation & $R^{2}$ & Significance level \\
\hline Spain & $2.7 E+07 x+240.0$ & 0.31 & 0.05 & $1.0 E+07 x+123.1$ & 0.64 & 0.01 \\
France & $-0.2 E+07 x+159.3$ & 0.02 & 0.7 & $0.11 E+07 x+85.6$ & 0.04 & 0.5 \\
Italy & $* * * *$ & 0.00 & 0.9 & $0.42 E+07 x+18.7$ & 0.62 & 0.01 \\
Africa & $4.6 E+07 x+312.0$ & 0.34 & 0.05 & $0.7 E+07 x+104.4$ & 0.78 & 0.01 \\
\hline
\end{tabular}

$R^{2}$ is the Pearson coefficient; the significance level corresponds to Fisher F-test and the independent variable; " $x$ " is the divergence value over the sea.

-0.15 and $-0.2 \mathrm{~cm} / \mathrm{s}$. These mean values are in good concordance with some modelling exercises performed under summer conditions in the Western Mediterranean [15-17] and with previous measurements obtained with summer meteorological soundings [17].

High values for the subsidence on the Western Mediterranean Sea are due to the synergetic sum of different processes $[8,18]$. On one hand, from a synoptic point of view, there is the influence of the Azores Anticyclone over the area and the prevailing subsidence in mid-latitudes regions associated to the Hadley circulation; on the other hand, from a mesoscale point of view, there is a deep and closed sea surrounded by high, steep, and semiarid mountains favouring the development of strong sea breezes and a daily oscillation of thermally driven tropospheric wind flows [10, 19-21].

As a result of this synergetic sum of meteorological processes governing the atmospheric motions at the different spatial scales, there is a clear seasonal evolution of sinking wind speeds over the Western Mediterranean (Figure 4) that is well correlated not only with the seasonal evolution of solar isolation and climatological temperatures that record maximum values in July [13], but also with other observables that are linked with the tropospheric dynamics in the Mediterranean like the seasonal evolution of the tropospheric ozone in the Western Mediterranean basin or the concatenation of transitional dispersive scenarios $[9,17,18,22,23]$.

Another relevant feature in Figure 4 is the alternation of positive and negative values of the divergence (or vertical wind speed). Positive values are obtained during the nocturnal hours and negative ones during the daytime. Despite the quasi-permanent anticyclone conditions prevailing on the WMB at the synoptic scale $[13,17]$, this result indicates a net convergence of horizontal winds during the night (forcing upwards motions of the air masses in the troposphere) and a divergence during the day (with downwards motions of the air masses). This daily "pulsation" of the direction of vertical motions can be explained if we considered that within the WMB there is a meso-alpha (tele)connection within the whole Western Mediterranean basin, where, during daytime, thermally driven circulations developed across the coasts compensate the tropospheric air mass inflow towards inland with sinking motions on the sea of air masses aloft, and where, during the nighttime, drainage flows coming from inland towards the sea together with a warm Mediterranean surface (in summertime) generate a relative low pressure in the Western Mediterranean (cyclonic upwards air mass movement at the meso-alpha scale). From a synoptic point of view, this tropospheric pulsation is seen as the "typical" daily cycle (weakening and strengthening) of the Atlantic anticyclone over the Mediterranean Sea [13, 17].

To finish with this section, it is relevant to note that the amplitude of the divergence curve increases from April to July and decreases from August to October (Figure 4); that is, divergence intensity is directly proportional to the annual variation of solar radiation. This is because the horizontal divergences over the sea are fed by compensatory subsidences that compensate the thermally driven coastal circulations (which are the result of the solar heating of the ground).

In the following section we discuss in more detail the relationship between the seasonality and daily pulsation of the subsidence strength on the sea and the daily cycles of mesoscale motions around the coasts of the WMB.

\section{Meso-Alpha Scale Atmospheric Interactions within the Western Mediterranean Basin}

To study meso-alpha scale tropospheric interactions, we have calculated statistical correlations between the daily pulsation of the mean subsidence calculated over the WMB (Figure 4) and the mean time evolution of wind direction on four different coastal areas around the WMB (Figure 1) from April to October (Figure 5). To study the time dependency of the interactions, we have considered the reanalysis data at $00 \mathrm{~h}$ and $06 \mathrm{~h}$ as nocturnal periods and at $12 \mathrm{~h}$ and $18 \mathrm{~h}$ as diurnal hours. Hours are always in Universal Time Coordinated (UTC).

After plotting the mean wind directions on the different coastal areas in front of the calculated mean divergence values over the sea, strong differences appear between seasons and also between diurnal and nocturnal values (Figure 5). Furthermore, in almost all cases, we have obtained quite reasonable correlations between both magnitudes although the significance levels found also depend on the site (Table 1).

During nighttime and regardless of the site, standard deviations are higher for nocturnal values than for diurnal values (Figure 5) because wind speeds are usually lower during nighttime. This feature also explains that the statistics obtained during the nocturnal hours are worse than those obtained with the diurnal values (Table 1). Furthermore, 

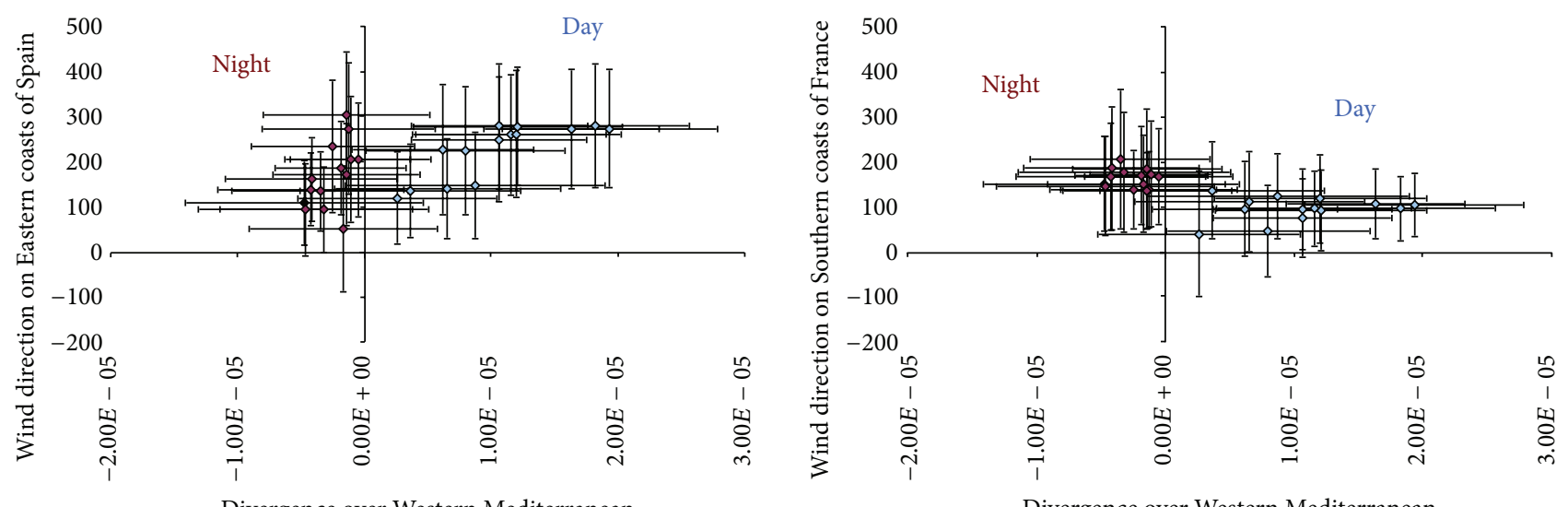

Divergence over Western Mediterranean

Divergence over Western Mediterranean
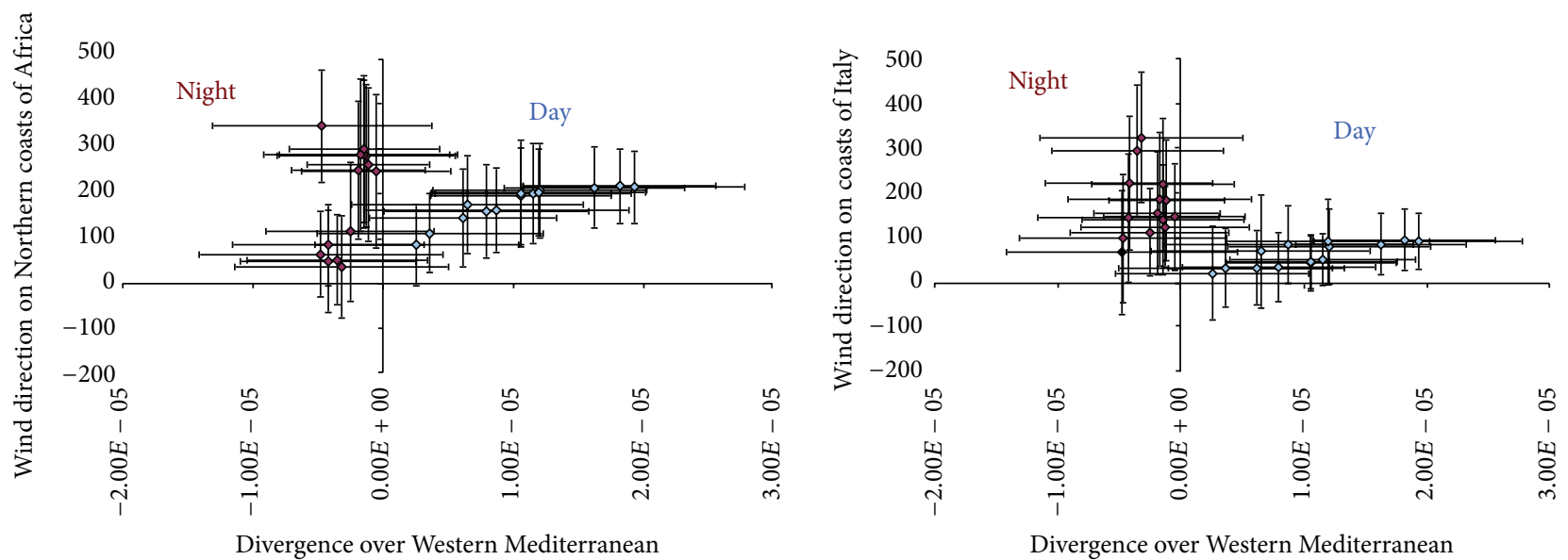

FIGURE 5: Daily (night and day) correlations between mean wind directions at four geographical coastal areas around the WMB and the corresponding mean divergence values over the sea. Standard deviations after the time-averages over the 15-year period are also plotted.

all the nocturnal values of wind direction are associated with near-zero negative divergences whilst higher (positive) divergence values are always linked with diurnal hours.

Polar plots (Figure 6) were done disaggregating seasonally (spring, summer, and autumn) and hourly (night, 12, and $18 \mathrm{~h}$ ) the available reanalysis data. In these polar plots, the distance to the origin of the axes is equal to the module (positive value) of the calculated mean divergence (for a given hour and season). The $y$-axis corresponds to the geographical North-South direction (being the North directed towards the positive $y$-axis) and the $x$-axis to the East-West direction (being the East directed towards the positive $x$-axis). Thus, wind flow direction (associated with each divergence value) determines the polar angle in the plot (with the origin of angles in the North and with the rest of positive values of angles plotted clockwise from the North). Angles in these plots indicate the mean direction towards the "mean air" is blowing at that time.

A remarkable feature in Figure 6, coherently to what was said when describing Figure 4, is that maximum divergences always correspond with the summer season whilst minimum divergences over the sea are always recorded in autumn.
During the spring, maximum values of the divergence are recorded in the late afternoon whilst at noon the divergence values are lower. Furthermore, on summer and spring seasons, regardless of the site, divergences are higher at 18:00 $\mathrm{h}$ than at 12:00 h.

During the highest solar isolation hours of the day the subsidence (divergence) on the Mediterranean reaches its maximum strength, increasing the atmospheric pressure on the lower layers of the atmosphere and driving anticyclone circulations that force the diurnal evolution of the direction of the sea breezes along all the Western Mediterranean coasts. Hence, except on the Gulf of Lyon, there is a reasonable good linear correlation between the angle (wind direction) and the intensity of the divergence over the sea, that is, with the hour of the day (Figure 6, Table 1). The worst diurnal linear correlation is found in the Gulf of Lyon, where other complementary meteorological processes also play an important role in the daily dynamics of the wind flow. Continental air masses coming from both the Cantabric Sea and Central Europe (Rône valley, French Pyrenees and Carcassonne gaps) inflow, through the Gulf of Lyon, in the Western Mediterranean basin as North-western winds. Subsidence of 

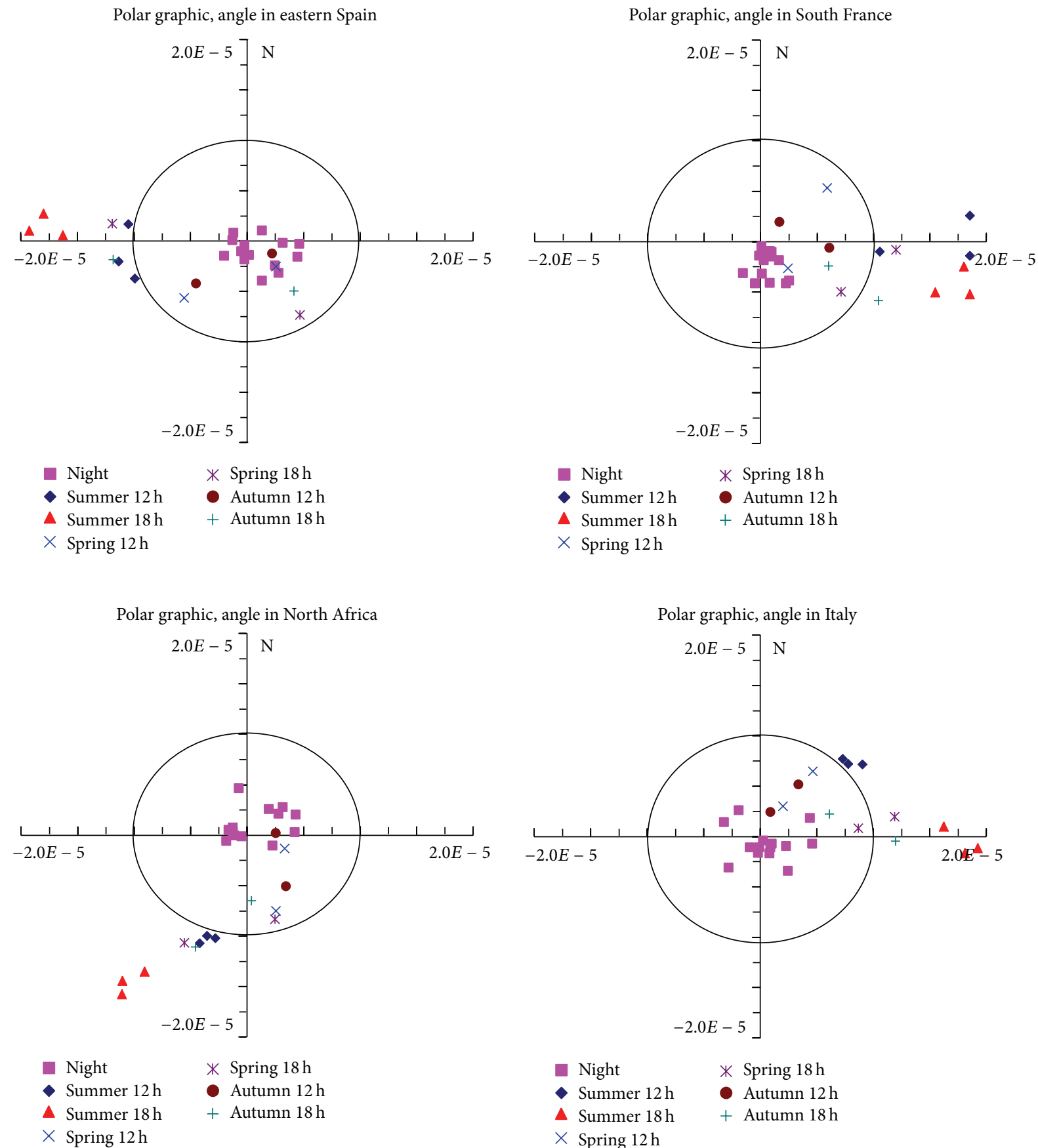

FIGURE 6: Polar plots of the angular distribution of the wind direction on four selected coastal areas versus mean divergence values over the WMB.

these flows over cold water in the Gulf of Lyon and Northwestern Mediterranean superimposes to the generalized compensatory subsidence on the Mediterranean Sea. Only very high values of divergence on the Mediterranean (i.e., during summertime) can perturb the direction of this inflow's winds, veering them towards East-Southeast. In spring, when divergence values on the Mediterranean are not as high as in summer, diurnal winds flow into the Mediterranean towards the Southeast. Despite the season, during nocturnal hours, wind flow is almost constant with direction towards the South-Southeast.

\section{Conclusions}

The availability of an extensive dataset of reanalysis meteorological fields provided by NCEP/NCAR shows the persistence of the main features of tropospheric dynamics in the WMB at the meso-alpha scale. 


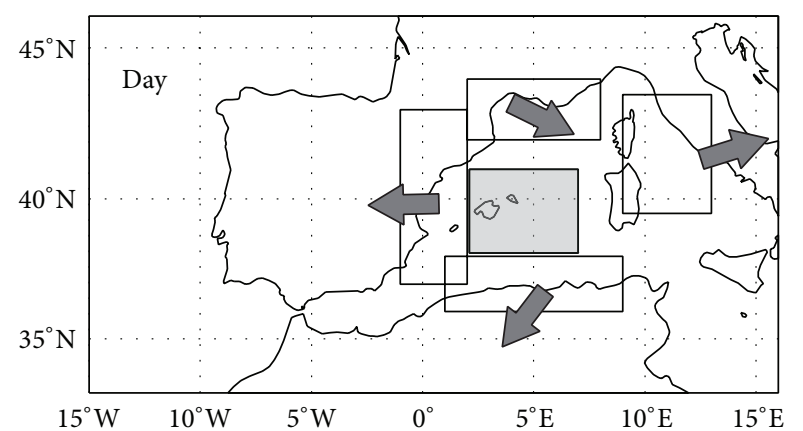

(a)

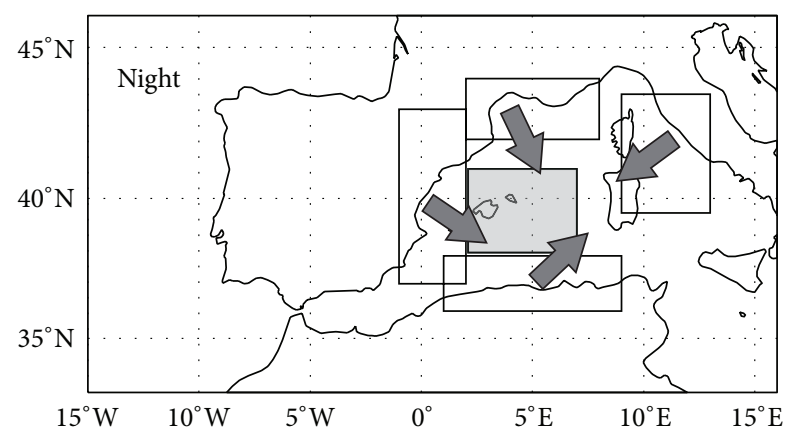

(b)

FIGURE 7: Schematic representation of the diurnal (a) and nocturnal (b) coastal wind fields in the WMB corresponding to a generalized subsidence (day) and convergence (night) over the Western Mediterranean Sea. Shaded rectangle represents the area where divergence values were calculated.

After a 15-year average of the reanalyses meteorological fields, between April and October, we have shown the mean seasonal evolution of the tropospheric dynamics in the Western Mediterranean as the result of the meso-alpha interaction between the daily oscillation of coastal thermally driven circulations around the WMB and the daily pulsation of sinking speeds over areas of the Western Mediterranean Sea. Furthermore, from the 15-year average, a persistent link (statistically significant correlation) has been found between these processes (daily oscillation of sea breezes and daily pulsation of subsidence/convergence on the WMB) elucidating their teleconnection and the seasonal evolution of the strength of this linkage.

Despite the location, during the nocturnal hours, winds around the WMB blow towards the Sea (accordingly to the nocturnal convergence seen in Figure 4); and during the daytime, wind directions at the different coasts in the WMB (and also their intensities) are all correlated with the activation of sinking motions over the sea (diurnal divergence seen over the Sea in Figure 4). In summertime, when mesoscale circulations are stronger, the pulsation of the generalized circulation in the WMB (Figure 6) is in a good agreement with the mean daily cycle of wind directions measured at different coastal sites around the basin (Figure 1).

These meso-alpha tropospheric interactions within the basin drive mean tropospheric dynamics in the WMB that responds to a general anticyclone flow of air masses during daytime and a weaker cyclonic flow during nighttime (Figure 7).

To include the effect of the noncaught mesoscale processes (meso-beta and meso-gamma scales) on the continuity of wind flows within the Mediterranean basin, it is necessary to perform the analysis presented in this paper with a database with a higher resolution. It is foreseen that the inclusion of meteorological processes (linked to spatial scales lower than 2.5 degrees) will reinforce the compensatory motions discussed herein. An increase in the temporal resolution of the reanalysis datasets will result also in a better understating of the persistence and evolution of the daily cycles and also the fine structure (convergence and compensatory subsidence areas) of the mesoscale flows. These aspects will be the aim of a future work.

\section{Conflict of Interests}

The authors declare that there is no conflict of interests in relation to this paper.

\section{Acknowledgments}

The CEAM Foundation is supported by the Generalitat Valenciana (Spain). This study has been partially funded by the Spanish Ministry of Science and Technology, through the research projects "MODELISMOS"-CGL2010-17623 and "GRACCIE"-CONSOLIDER-INGENIO2010 Program CSD2007-00067 and by the Conselleria de Cultura (Generalitat Valenciana, SPAIN) research projects "FEEDBACKS" and "DESESTRES"-PROMETEO Programs-P/2009/06 and PROMETEOII/2014/038. NCEP Reanalysis data was provided by the NOAA/OAR/ESRL PSD, Boulder, Colorado, USA, from their Web site at http://www.esrl.noaa.gov/psd/.

\section{References}

[1] NOAA/OAR/ESRL PSD, Boulder, Colo, USA, 2014, http://www .esrl.noaa.gov/psd/.

[2] R. Salvador, J. Calbó, and M. M. Millán, "Horizontal grid size selection and its influence on mesoscale model simulations," Journal of Applied Meteorology, vol. 38, no. 9, pp. 1311-1329, 1999.

[3] J. Lelieveld, H. Berresheim, S. Borrmann et al., "Global air pollution crossroads over the Mediterranean," Science, vol. 298, no. 5594, pp. 794-799, 2002.

[4] M. M. Millán, R. Salvador, E. Mantilla, and G. Kallos, "Photooxidant dynamics in the Mediterranean basin in summer: Results from European research projects," Journal of Geophysical Research D: Atmospheres, vol. 102, no. 7, pp. 8811-8823, 1997.

[5] G. Kallos, M. Astitha, P. Katsafados, and C. Spyrou, "Longrange transport of anthropogenically and naturally produced 
particulate matter in the Mediterranean and North Atlantic: current state of knowledge," Journal of Applied Meteorology and Climatology, vol. 46, no. 8, pp. 1230-1251, 2007.

[6] K. Velchev, F. Cavalli, J. Hjorth et al., "Ozone over the Western Mediterranean Sea-results from two years of shipborne measurements," Atmospheric Chemistry and Physics, vol. 11, no. 2, pp. 675-688, 2011.

[7] E. Kalnay, M. Kanamitsu, R. Kistler et al., "The NCEP/NCAR 40-year reanalysis project," Bulletin of the American Meteorological Society, vol. 77, no. 3, pp. 437-471, 1996.

[8] M. Millán, R. Salvador, E. Mantilla, and B. Artíñano, "Meteorology and photochemical air pollution in Southern Europe: experimental results from EC research projects," Atmospheric Environment, vol. 30, no. 12, pp. 1909-1924, 1996.

[9] M. M. Millán, E. Mantilla, R. Salvador et al., "Ozone cycles in the western Mediterranean basin: Interpretation of monitoring data in complex coastal terrain," Journal of Applied Meteorology, vol. 39, no. 4, pp. 487-508, 2000.

[10] M. Millán, B. Artiñano, L. Alonso, M. Castro, R. FernandezPatier, and J. Goberna, "Meso-Meteorological Cycles of Air Pollution in the Iberian Penisula, (MECAPIP) (Air Pollution Research Report 44, EUR No. 14834)," European Commision DG XII/E-1, Brussels, Belgium, 1992.

[11] J. L. Palau, G. Pérez-Landa, J. J. Diéguez, C. Monter, and M. M. Millán, "The importance of meteorological scales to forecast air pollution scenarios on coastal complex terrain," Atmospheric Chemistry and Physics, vol. 5, no. 10, pp. 2771-2785, 2005.

[12] K. J. Allwine and C. D. Whiteman, "Single-station integral measures of atmospheric stagnation, recirculation and ventilation," Atmospheric Environment, vol. 28, no. 4, pp. 713-721, 1994.

[13] H. J. Bolle, Ed., Mediterranean Climate: Variability and Trends, Springer, Berlin, Germany, 2003.

[14] J. R. Holton, An Introduction to Dynamic Meteorology, Elsevier, Academic Press, New York, NY, USA, 4th edition, 2004.

[15] R. Salvador, M. Millán, E. Mantilla, and J. M. Baldasano, "Mesoscale modelling of atmospheric processes over the Western Mediterranean area during summer," International Journal of Environment and Pollution, vol. 8, no. 3-6, pp. 513-529, 1997.

[16] G. Gangoiti, M. M. Millán, R. Salvador, and E. Mantilla, "Longrange transport and re-circulation of pollutants in the western Mediterranean during the project Regional Cycles of Air Pollution in the West-Central Mediterranean Area," Atmospheric Environment, vol. 35, no. 36, pp. 6267-6276, 2001.

[17] M. Millán, "Ozone dynamics in the Mediterranean basin. A collection of scientific papers resulting from the MECAPIP, RECAPMA and SECAP projects," Air Pollution Research Report 78, European Commission, Brussels, Belgium, 2002.

[18] J. L. Palau, G. Pérez-Landa, and M. M. Millán, “Transitional dispersive scenarios driven by mesoscale flows on complex terrain under strong dry convective conditions," Atmospheric Chemistry and Physics, vol. 9, no. 1, pp. 119-131, 2009.

[19] Y. Mahrer and R. A. Pielke, "The effects of topography on the sea and land breezes in a two-dimensional numerical model," Monthly Weather Review, vol. 105, no. 9, pp. 1151-1162, 1977.

[20] J.-F. Miao, L. J. M. Kroon, J. V.-G. de Arellano, and A. A. M. Holtslag, "Impacts of topography and land degradation on the sea breeze over eastern Spain," Meteorology and Atmospheric Physics, vol. 84, no. 3-4, pp. 157-170, 2003.

[21] J. Cuxart, J. Cunillera, M. A. Jiménez, D. Martínez, F. Molinos, and J. L. Palau, "Study of mesobeta basin flows by remote sensing," Boundary-Layer Meteorology, vol. 143, no. 1, pp. 143-158, 2012.
[22] J. L. Palau, G. Pérez-Landa, J. Meliá, D. Segarra, and M. M. Millán, "A study of dispersion in complex terrain under winter conditions using high-resolution mesoscale and Lagrangian particle models," Atmospheric Chemistry and Physics, vol. 6, no. 4, pp. 1105-1134, 2006.

[23] J. L. Palau and F. Rovira, "A methodology for the characterization of periodicities in nonsteady time series: application to tropospheric ozone recharging cycles in the western Mediterranean basin," Journal of Atmospheric and Oceanic Technology, vol. 29, no. 11, pp. 1644-1656, 2012. 

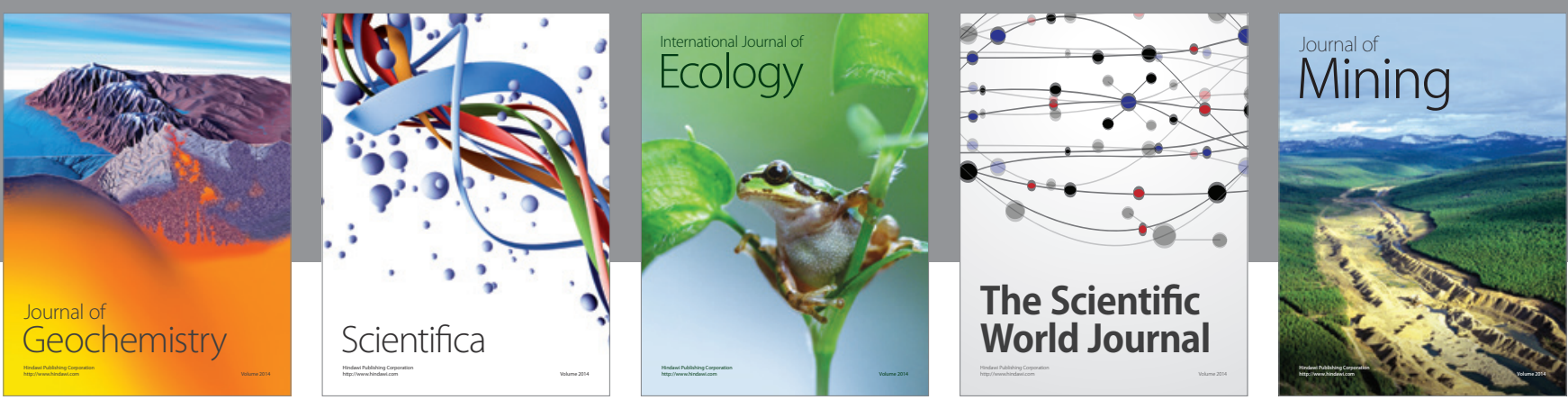

The Scientific World Journal
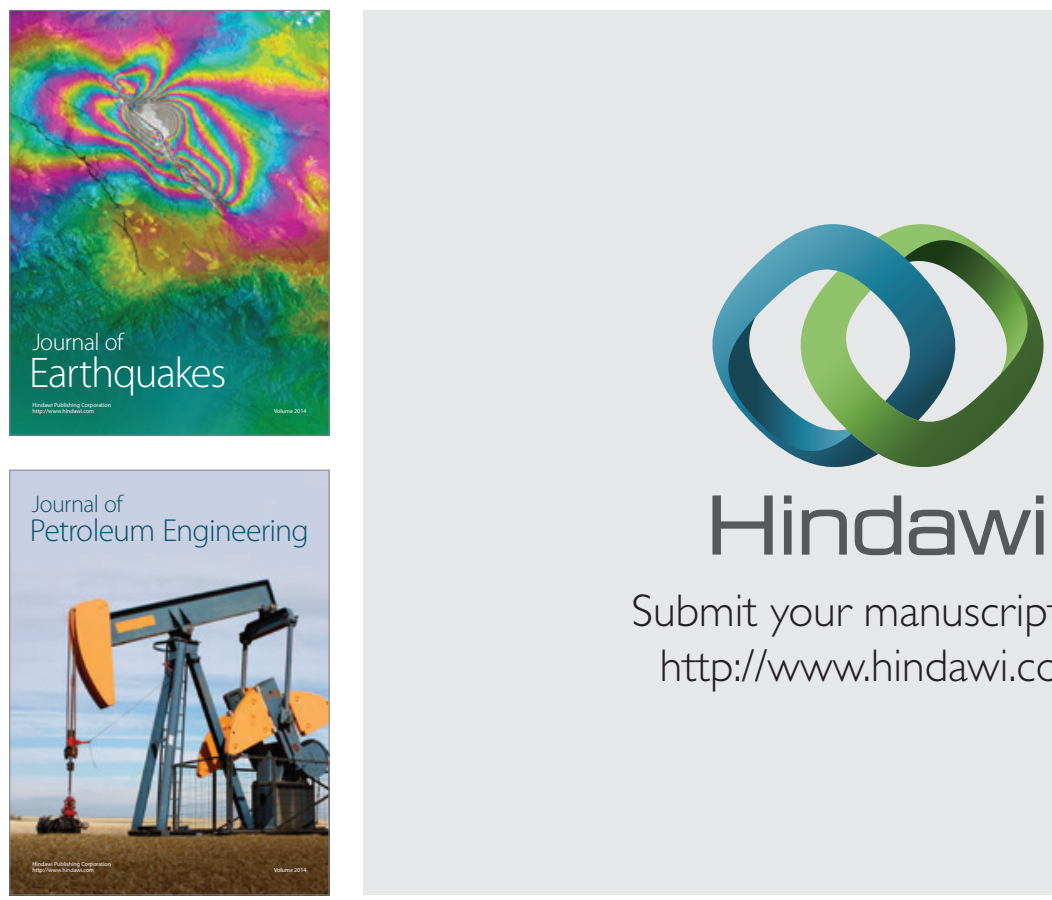

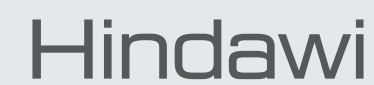

Submit your manuscripts at

http://www.hindawi.com
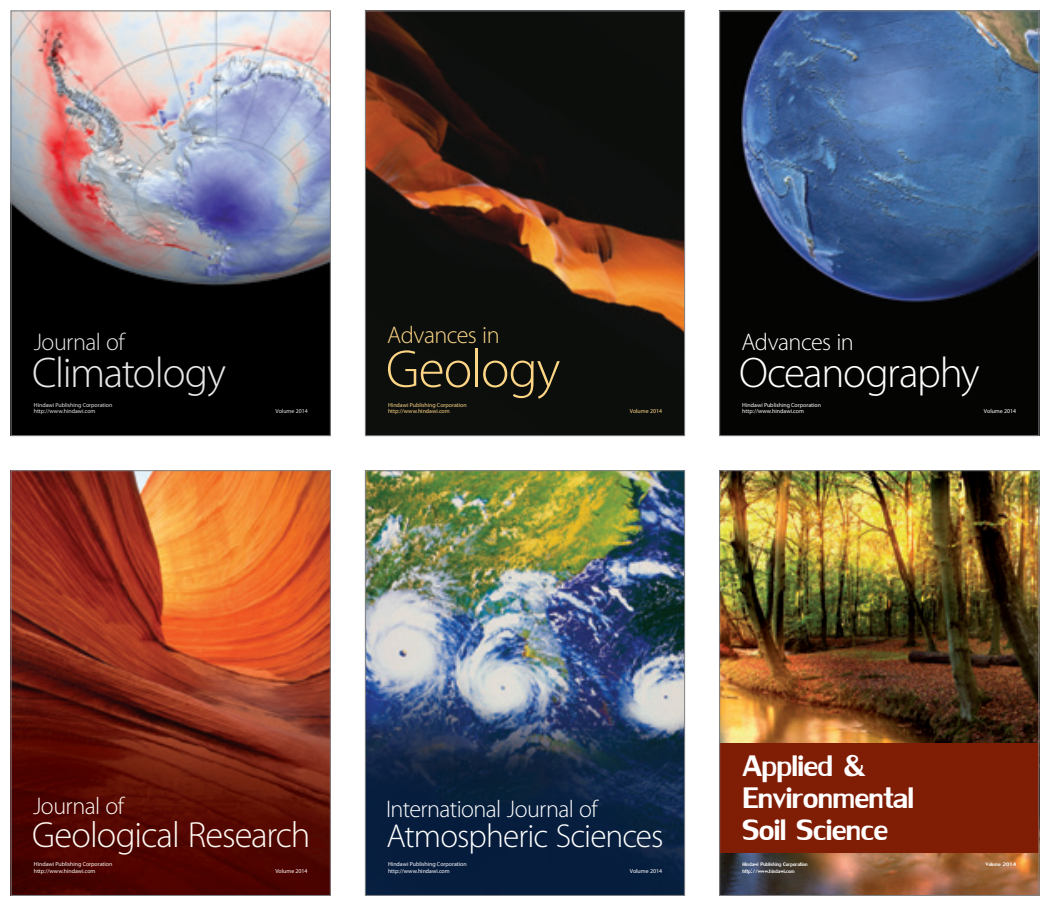
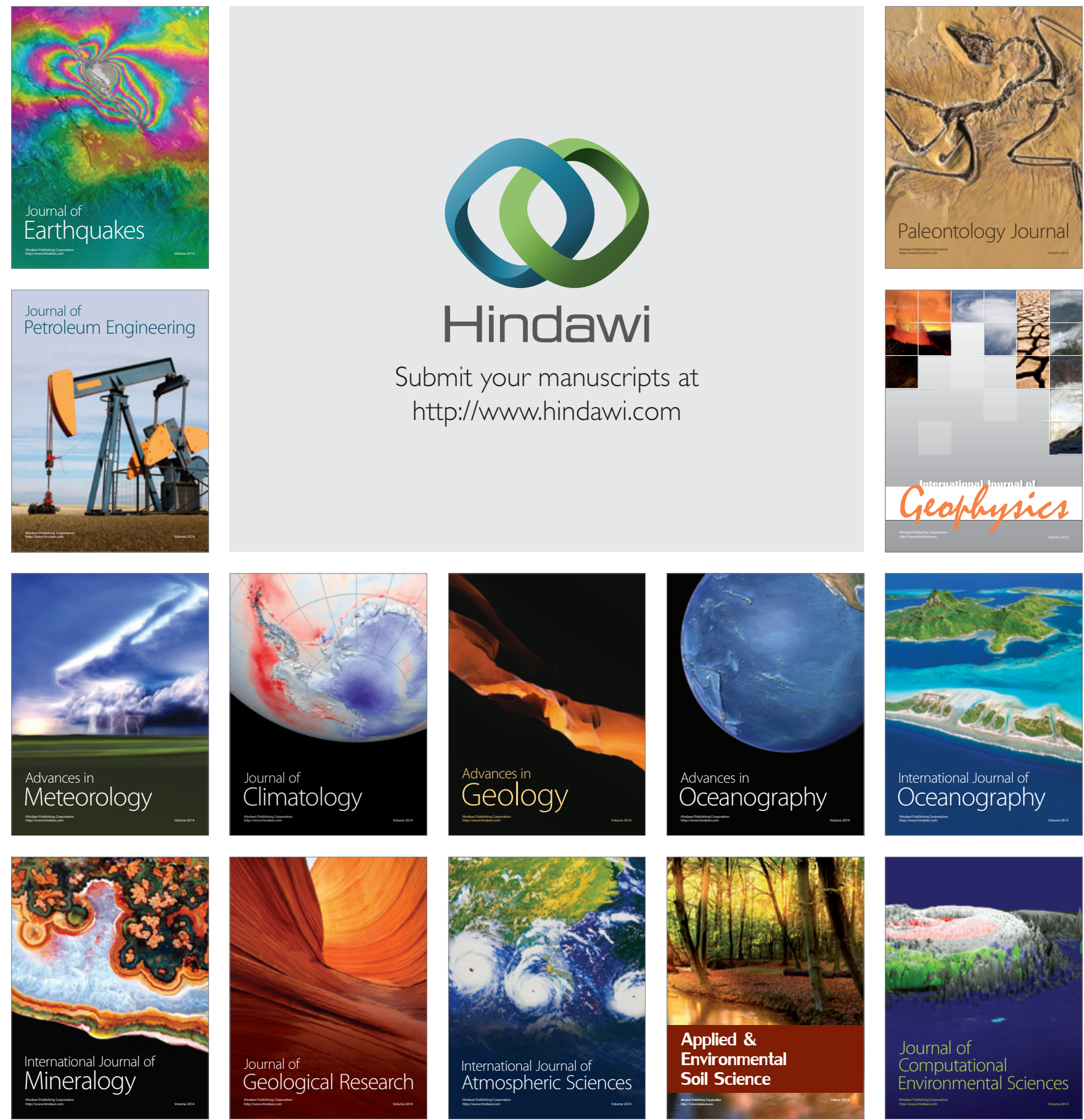